\title{
Surface Texture Analysis after Hydrostatic Burnishing on X38CrMoV5-1 Steel
}

\author{
Slawomir Swirad* ${ }^{*}$
}

\begin{abstract}
Ball burnishing is a plastic deformation process used as a surface smoothing and surface improvement finishing treatment after turning or milling processes. This process changes the surface stereometrics of the previously machining surface. Burnishing with hydrostatic tools can be easily and effectively used on both conventional and Computer Numeric Control (CNC) machines. The existing research of the burnishing process mainly focuses on the functional surface characterization, for example, surface roughness, wear resistance, surface layer hardness, etc. There is a lack of references reporting a detailed analysis of 3D parameters calculation with a mathematical model to evaluate the results of the ball burnishing. This paper presents the effect of ball burnishing process parameters with hydrostatic tools on the resulting surface structure geometry. The surface topography parameters were calculated using the TalyMap software. Studies were conducted based on Hartley's static, determined plan. Such a plan can be built on a hypersphere or hypercube. In this work, a hypercube was used. In the case of Hartley's plan makes it possible to define the regression equation in the form of a polynomial of the second degree. The input process parameters considered in this study include the burnishing rate, applied pressure, and line-to-line pitch. The significant influence of these parameters was confirmed and described as a mathematical power model. The results also showed a positive effect of hydrostatic burnishing on the roughness and geometric structure of the surface.
\end{abstract}

Keywords: Ball burnishing, Hydrostatic burnishing, Surface structure

\section{Introduction}

Surface quality plays a very important role in the proper formation of the properties of the machine part components. These properties can positively influence, e.g., the resistance to wear, corrosion and fatigue strength. Conventional methods such as machining, turning or milling very often don't allow to obtain the surface of appropriate parameters of a geometric surface structure. This kind of processing also causes unfavourable tensile residual stresses in the surface layer. These stresses have a negative impact on the resistance to work in fatigue conditions [1]. Burnishing allows to improve the properties of a surface layer by its plastic deformation. Ball burnishing is a chipless finishing process that allows to reduce the surface roughness and makes the surface work-hardened. In addition, compressive stresses that allow to increase

\footnotetext{
*Correspondence: s.swirad@prz.edu.pl

Faculty of Mechanical Engineering and Aeronautics, Rzeszow University of Technology, Powstancow Warszawy 12, 35-959 Rzeszow, Poland
}

the fatigue strength are introduced in the surface layer. A ball burnishing process consists of pressing and turning a smooth and very hard ball on the material surface in order to achieve plastic deformation of the surface roughness. This process can be implemented for a variety of surfaces, for example cylindrical, flat, internal as well as external. It can be used on conventional and CNC machines. Ball burnishing is very economical and, in some cases, it may replace operations such as grinding or polishing [2,3].

From an economic point of view, burnishing is significantly less expensive than grinding. Grinding requires sophisticated and expensive machine tools, while burnishing can be accomplished on any precision lathe. In addition, grinding cannot be conducted with other operations on the same machine tool, whereas burnishing can be performed on the same lathe used to conduct rough and fine turning $[4,5]$.

Burnishing can be widely used with various materials such as aluminium, steel [6-8], alloys [9, 10], and brass 
[11]. The effect of ball burnishing on the surface stereometric structure is most commonly described in research reviews. The parameters of greatest concern are the feed, force, and speed. The force plays a vital role in the ball burnishing process. From the start of the plastic deformation, increasing the force causes the surface roughness to decrease until it reaches a reasonably low value. However, an excessively high force may result in spalling of the surface [12].

The conducted literature review indicates that the main research area of different authors include primarily the characteristics of the surface geometric structure after ball burnishing. Most attention was focused on the description of the changes of the surface geometric structure parameters in regard to the process input parameters, i.e., burnishing force, feed rate, burnishing speed or the number of passes. Not much attention was paid to the mathematical description of the input parameters influence on the surface geometrical structure parameters. El-Tayeb et al. [13] analysed the impact of the following ball burnishing parameters: a ball diameter, burnishing speed, its force and direction on reducing roughness and improving tribological properties of aluminum 6061. Rao et al. [14] studied the impact of the parameters of burnishing and lubricant on the surface hardness of dual-phase steels. Loh et al. [15] investigated the possibility of optimizing (minimizing) the surface roughness for aluminum alloy. El-Taweel and El-Axir [16] studied the applicability of the Taguchi method for optimizing the process of ball burnishing. The parameters such as surface roughness and surface microhardness were taken into account. Shiou and Hsu [17] analysed the possibility of using ball burnishing for flat surfaces for stainless mould steel with the Taguchi plan for 9 experiments. In his further works Shiou and Cheng [18] analysed the impact of the ball burnishing parameters for free form surface plastic injection mould in order to obtain the best possible surface quality. Swirad et al. [19] analysed the influence of a burnishing strategy (raster and spiral) on the obtained surface geometric structure for martensitic steel. The results show that the raster strategy is a good solution for the curved-shaped surfaces due to the process stability in relation to the tool position and burnishing force. In his further works, Swirad [20] presented the possibility of ball burnishing for alphabeta titanium alloy (Ti6Al4V). The studies showed that there is a possibility of a significant reduction in the surface roughness in a wide range of the input parameters. In Ref. [21] the possibility of using hydrostatic burnishing for hard steel $145 \mathrm{Cr} 6$ with the hardness of 54 HRC was presented. The results showed that the burnishing force has the least impact on the reduction of the surface roughness. Burnishing width and speed has the biggest impact. In his works, López de Lacalle et al. [22] used two types of steel, AISI P20 steel of the hardness of HRC 32 and $\mathrm{H} 13$ tempered steel of the hardness of 52 HRC. The ball burnishing process was carried out in two directions (perpendicular and parallel) in relation to the preceding milling processing. The results indicate that for the perpendicular direction for the previous treatment a greater minimization of the surface roughness was achieved. In addition, it was revealed that for the steel with the hardness of HRC 32 the best results were achieved for the burnishing force of $15 \mathrm{MPa}$, while for the steel of the hardness of $52 \mathrm{HRC}$, it was necessary to apply the force of over $20 \mathrm{MPa}$. In another work, López de Lacalle et al. [23] used ball burnishing on the 5-axis CNC machine. As a workpiece, a hemisphere surface of AISI 1045 steel was used. The research findings indicate that continuous burnishing allows to achieve a significant reduction in the surface roughness. However, this treatment is limited by the maximum speed of the machine headstock (or table) rotary axes. In addition, the programming process of a burnishing path is more complex in the continuous five-axis.

In the present work, the Hartley research plan was used in order to obtain a mathematical description in the form of the equation of the input parameters impact of a ball burnishing process on the selected parameters of a geometric structure. As the input parameters, burnishing pressure, speed and width were analysed. The output parameters for the surface texture included $\mathrm{Sa}, \mathrm{Sv}, \mathrm{Sz}$, and Sq.

\section{Experimental Work}

$\mathrm{X} 38 \mathrm{CrMoV} 51$ steel was used as the sample material, which is a chromium-molybdenum alloy steel intended for hot work. Steel is used for elements of moulds for pressure die casting, extrusion tools for low-melting alloys, die inserts, dies, punches, etc. It is also used in the loaded parts of presses for the extrusion of tubes and rods. For these applications, the steel must retain its properties up to $600^{\circ} \mathrm{C}$. This can be achieved through the use of tungsten and molybdenum as alloying additions. This steel has very good mechanical properties, such as high tensile strength and hardness (HRC 54 to $100{ }^{\circ} \mathrm{C}$ ), high yield strength (up to $2200 \mathrm{MPa}$ ), high abrasion resistance, and high density $\left(7.85 \mathrm{~g} / \mathrm{cm}^{3}\right)$. The chemical composition is summarised in Table 1.

A photograph of the sample to be processed by ball burnishing is shown in Figure 1. The test specimens were milled, and medium-quality surface roughness texture was achieved using the general condition of grinding.

Aloxite discs of type 60MVBA were used for the grinding operation with a grinding wheel size of $210 \mathrm{~mm}$ at $2800 \mathrm{r} / \mathrm{min}$, a table speed of $6 \mathrm{~m} / \mathrm{min}$, and a cut depth of 
Table 1 Chemical composition of the specimens (\%)

\begin{tabular}{lllllll}
\hline $\mathbf{C}$ & $\mathbf{M n}$ & Si & $\mathbf{P}$ & $\mathbf{S}$ & $\mathbf{C r}$ & $\mathbf{M o}$ \\
\hline 0.42 & 0.5 & 1.2 & 0.03 & 0.03 & 5.5 & 1.5 \\
\hline
\end{tabular}
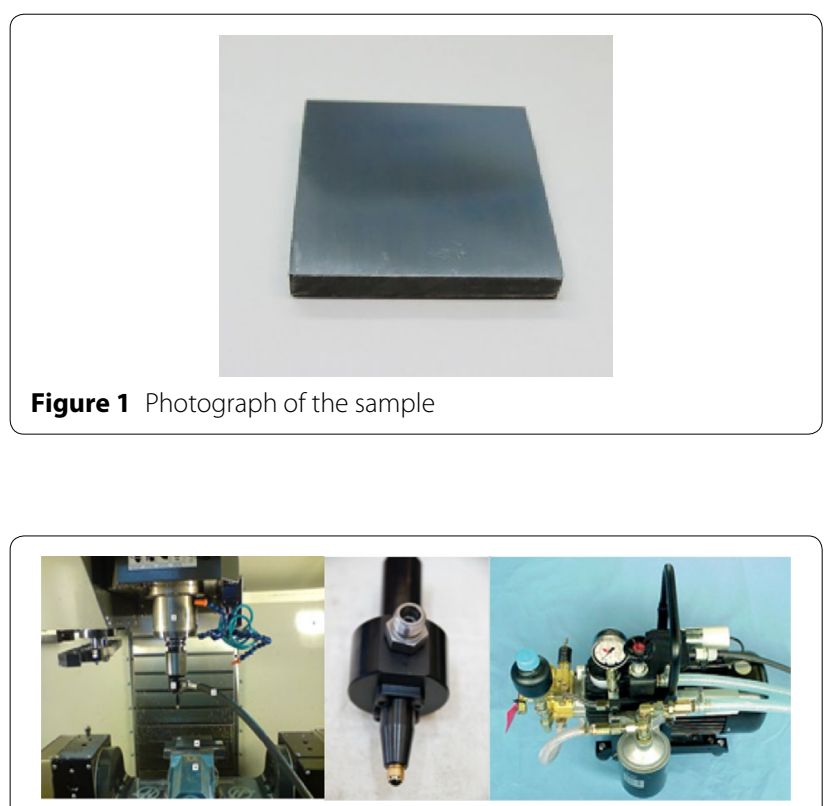

Figure 2 HASS CNC machine, burnishing tool, and high-pressure pump used in this study

$10 \mu \mathrm{m}$. A medium-quality surface roughness texture was achieved; the initial surface roughness was $\mathrm{Sa}=0.38 \mu \mathrm{m}$. The sample hardness was 48 HRC.

\subsection{Hydrostatic Burnishing Tools}

The burnishing process in this study was conducted using a HASS CNC centre (VF-1), as shown in Figure 2. The Ecoroll burnishing system used in this study consists of a high-pressure hydraulic pump (model 4.0 HGP) and the $6 \mathrm{~mm}$ diameter burnishing tool, which are connected via high-pressure hoses. The pressure was supplied by the hydraulic pump, which is equipped with its own coolant tank. The burnishing tool is based on the hydrostatic principle; the key element is a $6 \mathrm{~mm}$ ceramic ball. A hydrostatic pressure (maximum of $40 \mathrm{MPa}$ ) is applied behind the ball. This pressure generates a maximum normal force of $1000 \mathrm{~N}$, which presses the ball against the workpiece. For hard materials, a single-point burnishing tool is most effective because the small contact area involved allows for reasonable normal forces. The ball is supported by the fluid (coolant), and thus it can rotate in any direction.

A tool with a ball supported by fluid offers several advantages: (a) the hard ceramic ball makes it possible to burnish hardened steel (up to 65 HRC), (b) the ball material (ceramic) has a low adhesion to the workpiece material, (c) free rotation of the ball without contacting the retainer prevents any sliding between the burnishing tool and the workpiece. The burnishing process parameters considered in this study were burnishing pressures of 10,15 , and $20 \mathrm{MPa}$, burnishing speeds of 1000,2000 , and $3000 \mathrm{~mm} / \mathrm{min}$, and burnishing widths of $0.04,0.06$, and $0.08 \mathrm{~mm}$.

\subsection{Experimental Procedure}

In production engineering, problems with determining the impact of the input parameters of a particular process on its results are solved by doing active experiments, i.e., these in which: the values of the input parameters are assumed (in various combinations) on the predetermined levels, a process is realised, the results are developed, and the defined relations are presented in the form of a mathematical model. In order to achieve appropriate models with a possibly small number of experiments, the input factor values must be adopted according to the precise plans of experiments, and the results of these experiments must be developed in accordance with an appropriate, for a given plan, methodology described in Refs. [24-26].

In this article the studies were realised according to the static, determined, sequential, polyselectional (PS/ DK) Hartley's plan. It is a three-leveled plan built on a hypercube, which requires to set the input factors only on three equidistant levels. The latter allows to study the processes in which there is no possibility of an infinitely variable adjustment of the input parameters. The adopted plan was verified in other studies with good results [27, 28 ] and it allows to determine the function of the object of the studies as a second-order polynomial, with regard to the interaction of the input factors to be convenient for a mathematical analysis and model studies. It consists of three blocks of experiments:

- fractional repetition of experiment type PS/DK 2n,

- experiments at stellar points with arm $\alpha=1$,

- experiments at the plan central point.

The three-level planning is performed by encoding the factors as input variables at three levels:

- higher: marked as “+”, 
- mean (basic, zero): marked as "0",

- lower: marked as “-”.

The burnishing process parameters considered in this study were the burnishing pressure force, burnishing speed, and burnishing width. Other parameters were held constant, as their effect was not found to be significant in preliminary studies. The design matrix is given in Table 2 . The number of rows in the matrix corresponds to the number of experiments to be performed, signifies a coded value that is the average of the results of the measurements in an $i$ th experiment for each output factor. A simplified notation is used in the matrix in which, while determining the level of the input factor, ones are excluded.

The test results obtained in the experiments conducted based on this plan were subject to evaluation of the repeatability conditions of the experimental implementation. This requires a comparison of the variance results. The variance of the results for one experiment deviating with respect to the results of the other tests may indicate an atypical experience, and such an experiment should be repeated. The repeatability (stability) of the research conditions is assessed with Cochran's criterion by making a comparison of the measurement result variance. With the adopted level of significance (0.05), and with a critical value of Cochran's statistics, an empirical value of $\mathrm{G}$ coefficient is compared.

As a result of the experiments carried out according to the PS /DS-P:Ha3 plan, a mathematical model of the studied process (as a regression equation) is received as:

$$
y=b_{0}+\sum b_{k} x_{k}+\sum b_{k k} x_{k}^{2}+\sum b_{k j} x_{k} x_{j}
$$

The assessment of regression coefficients significance comes down to the comparison of the calculated values with critical values. If an absolute value of a given coefficient is higher than a critical value, then it is considered to be significant, if not, it is considered insignificant and a given word is rejected from the regression equation.

The adequacy of the regression equation was tested using the Fisher-Snedecor test, which includes the following.

- Calculation of the variance adequacy:

$$
S_{a d}^{2}=\frac{r_{i} \sum_{i=1}^{N}\left(\widehat{y}_{i}-\bar{y}_{i}\right)^{2}}{N-k-1},
$$

where $r$ is the number of repetitions, $N$ is the number of experiments, $k$ is the number of factors in the regression equation after discarding insignificant terms, and $y_{i}$ is the mean value of the process factor in the $i$ th experiment.

- Calculation of the empirical value of $F$ :

$$
F=\frac{S_{a d}^{2}(y)}{S^{2}(y)}
$$

The regression equation was considered adequate for the experimental results if $F<F_{\mathrm{kr}}$, based on the adopted significance level of $\alpha=0.05$.

The studies were conducted as described above and

\begin{tabular}{|c|c|c|c|c|c|c|}
\hline \multirow[t]{2}{*}{ Expt. No. } & \multicolumn{3}{|c|}{ Coded values } & \multicolumn{3}{|c|}{ Actual values } \\
\hline & $x_{1}$ & $x_{2}$ & $x_{3}$ & $\begin{array}{l}x_{1} \\
\text { Pressure } \\
\text { force } \\
P(\mathrm{MPa})\end{array}$ & $\begin{array}{l}x_{2} \\
\text { Speed } \\
V(\mathrm{~mm} / \mathrm{min})\end{array}$ & $\begin{array}{l}x_{3} \\
\text { Width } \\
a(\mathrm{~mm})\end{array}$ \\
\hline 1 & + & + & + & 20 & 3000 & 0.08 \\
\hline 2 & + & - & - & 20 & 1000 & 0.04 \\
\hline 3 & - & + & - & 10 & 3000 & 0.04 \\
\hline 4 & - & - & + & 10 & 1000 & 0.08 \\
\hline 5 & + & 0 & 0 & 20 & 2000 & 0.06 \\
\hline 6 & - & 0 & 0 & 10 & 2000 & 0.06 \\
\hline 7 & 0 & + & 0 & 15 & 3000 & 0.06 \\
\hline 8 & 0 & - & 0 & 15 & 1000 & 0.06 \\
\hline 9 & 0 & 0 & + & 15 & 2000 & 0.08 \\
\hline 10 & 0 & 0 & - & 15 & 2000 & 0.04 \\
\hline 11 & 0 & 0 & 0 & 15 & 2000 & 0.06 \\
\hline
\end{tabular}
mathematical models (in the form of the second degree

Table 2 Experimental design matrix 
polynomials), describing the influence of the ball burnishing parameters on the surface condition, were obtained.

The sample was measured using a Talysurf CCI white light interferometer. The number of measurement points was $1024 \times 1024$ in an area of $3.3 \times 3.3 \mathrm{~mm}^{2}$; the height resolution was $0.01 \mathrm{~nm}$. The forms were removed using a third-degree polynomial. The surface topography parameters were then calculated using the Talymap Gold software. The parameters from the ISO 25178 standard were then analysed [29].

Height parameters:

- Sq: root mean square height of the surface,

- Ssk: skewness of the height distribution,

- Sku: kurtosis of the height distribution,

- Sp: maximum height of the peaks,

- Sv: maximum height of the valleys,

- Sz: maximum height of the surface,

- Sa: arithmetical mean height of the surface.

Functional parameters:

- Spk: reduced peak height,
- Sk: core roughness depth,

- Svk: reduced valley depth.

Feature parameters:

- Spd: density of the peaks,

- Spc: mean peak curvature.

\section{Results and Discussion}

Figures 3, 4, 5, and 6 show selected 3D views of the surface and the surface profile for experiments in the implemented Hartley's plan. The ranges of the values of individual surface parameters for the burnished and ground samples are listed in Table 3.

The surface texture analysis shows that the ground surface has a high level of isotropy.

The values of parameter Sa ranged from 0.0557-0.142 $\mu \mathrm{m}$, Sq ranged from $0.0964-1.85 \mu \mathrm{m}$, and $\mathrm{Sz}$ ranged from $1.06-2.32 \mu \mathrm{m}$; the highest roughness value $(\mathrm{Sa}=0.142$ $\mu \mathrm{m})$ corresponds to the greatest pressure $(20 \mathrm{MPa})$. The surfaces after ball burnishing are anisotropic (Figure 7). No correlation was observed between the values of the spatial parameter and the amplitude parameters. The
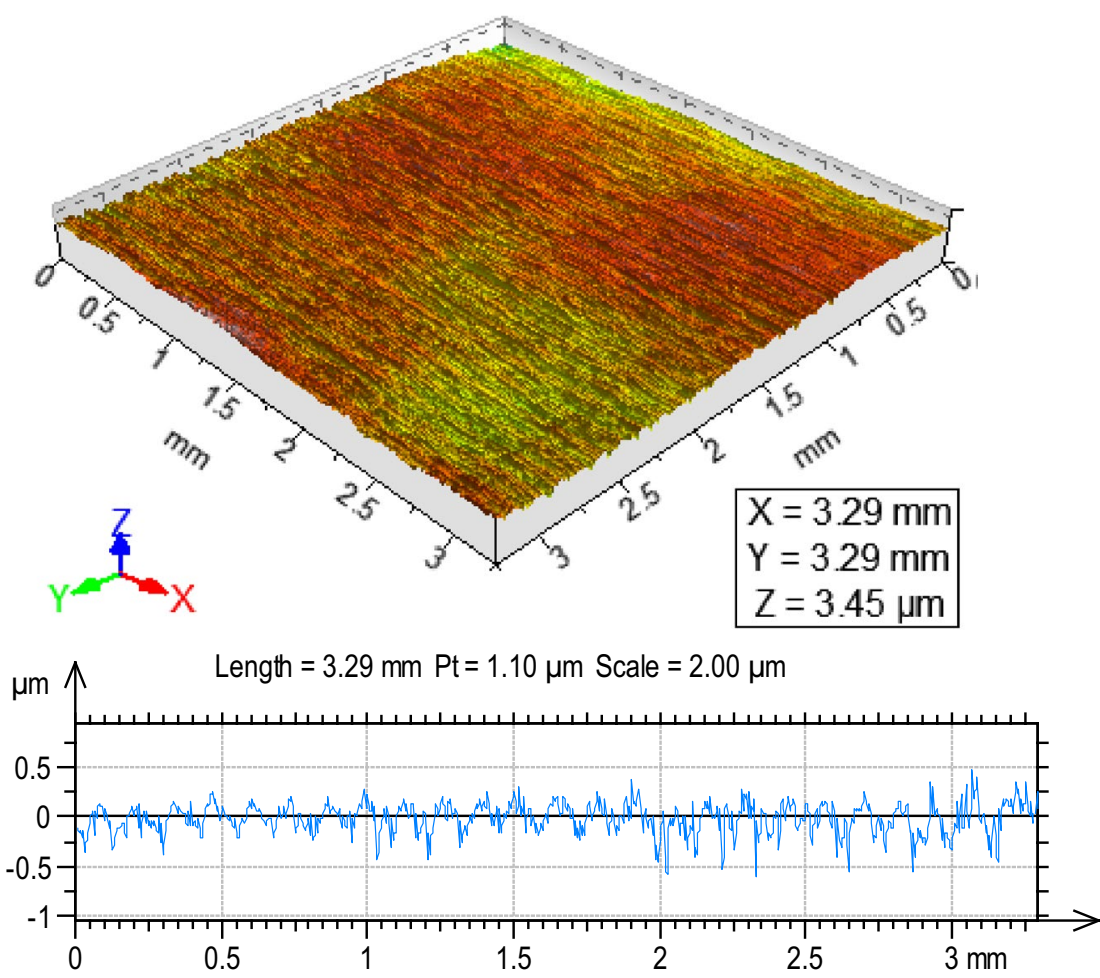

Sq: $0.098 \mu \mathrm{m}$

Ssk: -0.174

Sku: 4.17

Sp: $0.747 \mu \mathrm{m}$ Sv: $0.941 \mu \mathrm{m}$ Sz: $1.69 \mu \mathrm{m}$ Sa: $0.0756 \mu \mathrm{m}$ Spd: $472 / \mathrm{mm}^{2}$ Spc: $20.1 / \mathrm{mm}$ Sk: $0.219 \mu \mathrm{m}$ Spk: $0.0788 \mu \mathrm{m}$ Svk: $0.102 \mu \mathrm{m}$

Figure 3 Topography and parameters of the surface in Expt. No. 2 after burnishing 


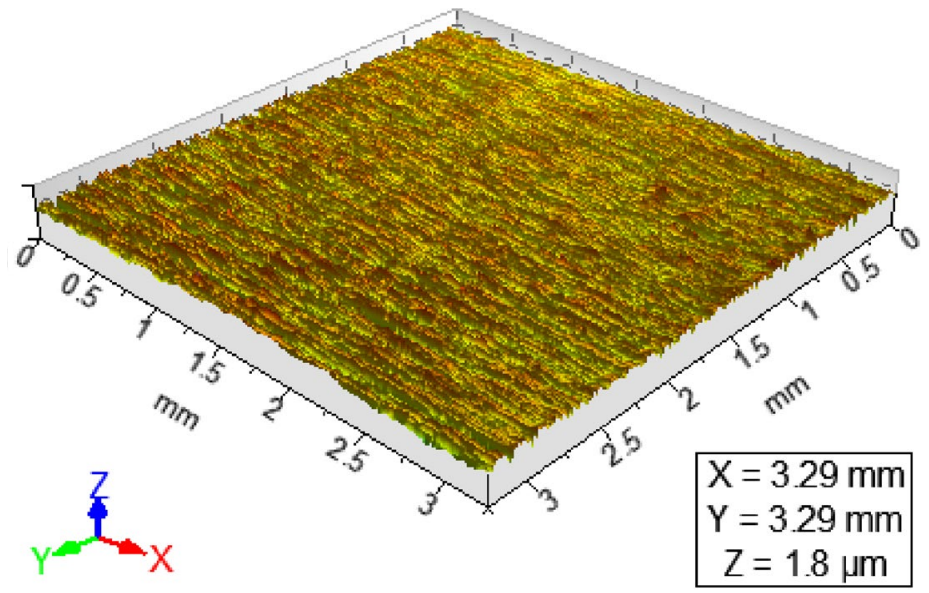

Sq: $0.119 \mu \mathrm{m}$

Ssk: -0.765

Sku: 5.17

Sp: $0.686 \mu \mathrm{m}$

Sv: $1.11 \mu \mathrm{m}$

Sz: $1.80 \mu \mathrm{m}$

Sa: $0.091 \mu \mathrm{m}$

Spd: $221 / \mathrm{mm}^{2}$

Spc: $16.1 / \mathrm{mm}$

Sk: $0.266 \mu \mathrm{m}$

Spk: $0.0862 \mu \mathrm{m}$

Svk: $0.166 \mu \mathrm{m}$

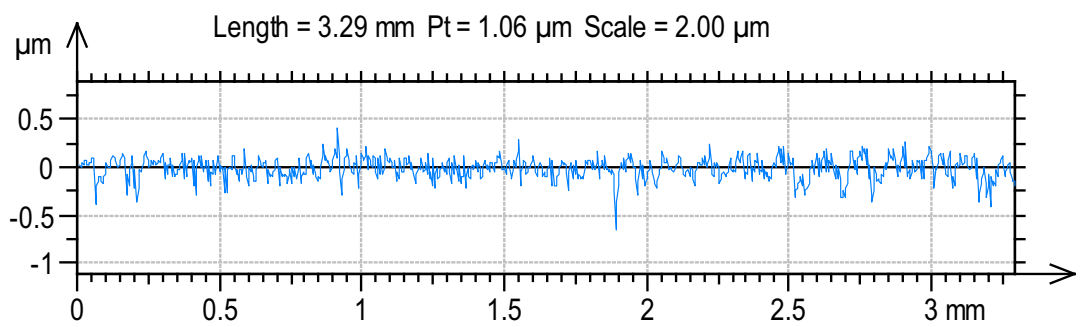

Figure 4 Topography and parameters of the surface in Expt. No. 5 after burnishing

density of peaks declined with the treatment, and the lowest value was $219 / \mathrm{mm}^{2}$. As a result of burnishing, a significant reduction in the surface roughness occurred.

The distribution of the ordinates is close to a normal distribution with a small negative skewness $($ Ssk $=-0.245, \mathrm{Sku}=3.12)$. The values of the amplitude parameters are as follows: $\mathrm{Sa}=0.387 \mu \mathrm{m}, \mathrm{Sq}=0.488 \mu \mathrm{m}$, and $\mathrm{Sz}=6.06 \mu \mathrm{m}$.

\section{Mathematical Model of the Ball Burnishing Process}

The basis for the development of mathematical models defining the relationship between the burnishing process parameters (process factors) and the selected results parameters are the results of the tests presented in the previous section. Based on these results, for the mathematical models, four surface texture parameters were selected as result parameters; the values of these parameters obtained from measurements and calculations are listed in Table 4.

The results in Table 4 were processed according to the mathematical method described in Section 2.2, substituting the values of corresponding parameters from Table 3 successively as the output factor (y). This procedure was repeated four times consecutively for each factor to produce four models in the form of second-order polynomials to describe the influence of the ball burnishing parameters on the values of surface texture parameters.

The procedure for the processing of the results included:

- calculation of the regression coefficients,

- calculation of the variance measurement errors, $\mathrm{S}^{2}(\mathrm{y})$,

- assessment of the reproducibility of the experimental conditions using the Cochran criterion,

- calculation of the regression coefficients,

- assessment of the significance of the coefficients in the regression equation.

After the rejection of negligible coefficients and decoding, the regression equations take the following forms:

$$
\begin{aligned}
S a= & 0.1089+42.92 a^{2}+a(-2.49-0.0875 P-0.00038 V) \\
& +P(0.03109-0.000816 P-0.0000011 V) \\
+ & 0.000042 V \\
S z= & -0.403+72.9 a+0.0158 P-2.35 a P \\
& -0.00096 P^{2}-0.000567 V-0.00975 a V \\
& +0.000077 P V
\end{aligned}
$$




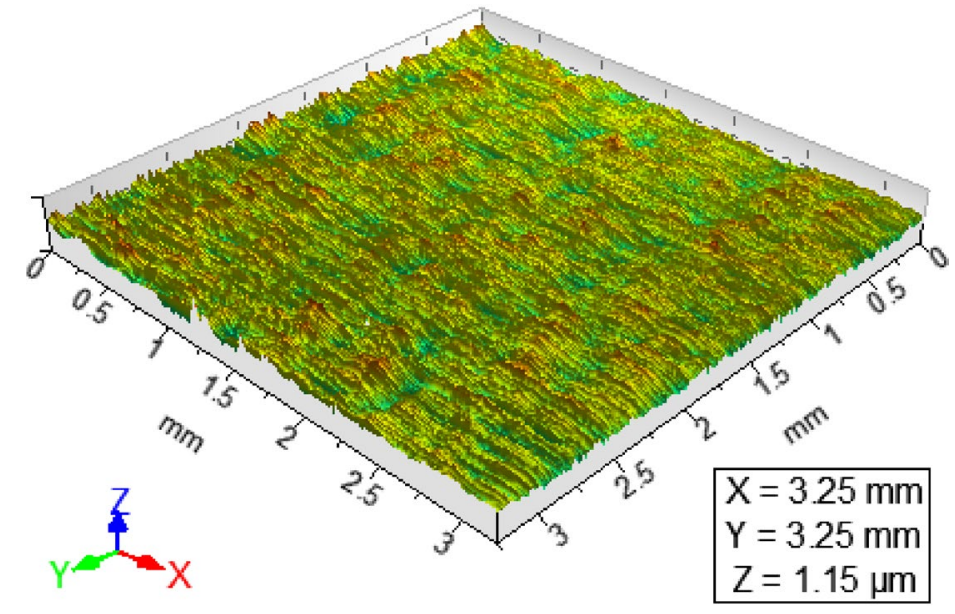

Sq: $0.0946 \mu \mathrm{m}$

Ssk: -0.405

Sku: 3.87

Sp: $0.563 \mu \mathrm{m}$

Sv: $0.608 \mu \mathrm{m}$

Sz: $1.17 \mu \mathrm{m}$

Sa: $0.0738 \mu \mathrm{m}$

Spd: $225 / \mathrm{mm}^{2}$

Spc: $9.60 / \mathrm{mm}$

Sk: $0.219 \mu \mathrm{m}$

Spk: $0.0714 \mu \mathrm{m}$

Svk: $0.116 \mu \mathrm{m}$

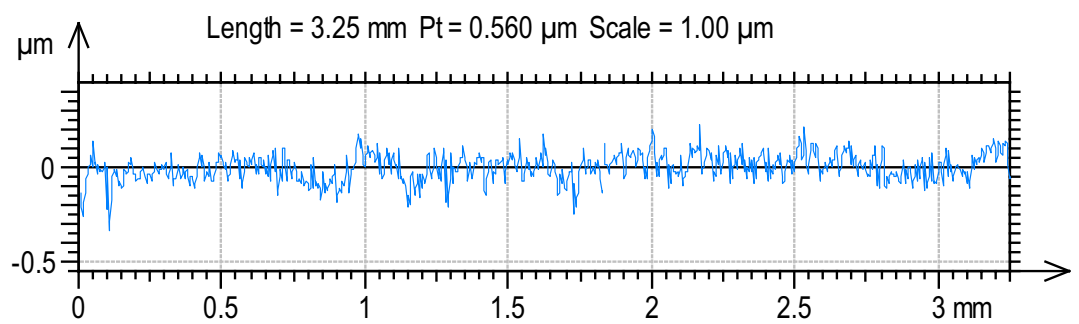

Figure 5 Topography and parameters of the surface in Expt. No. 7 after burnishing

$$
\begin{aligned}
S v= & 0.1955+2.1 a+0.0344 P-0.125 a P \\
& -0.001064 P^{2}+0.00004014 V-0.000525 a V \\
& +0.0000018 P V-8.9 \times 10^{-9} V^{2}, \\
S q= & -3.494+96.1 a-252.5 a^{2}+0.213 P \\
& -2.34 a P-0.0058 P^{2}-0.000183 V \\
& -0.00955 a V+0.0000504 P V .
\end{aligned}
$$

The results of the analysis were verified by an assessment of the adequacy of the regression equation, which indicated that all of the resulting equations are adequate at a significance level of $\alpha=0.05$.

All of the resultant mathematical models indicate a non-linear relationship between the obtained process values for the result factors and the process parameters for processing with a hydrostatic tool. Squared elements present in all equations indicate the existence of extremes (optima) in the tested function within the range of the variation in the process parameters. To determine these, it is necessary to carry out optimisation.

\section{Conclusions}

(1) A ball burnishing method with hydrostatic tools can be used to machine steel components of $\mathrm{X} 38 \mathrm{Cr}$ MoV51 with a hardness of 48 HRC efficiently, provided a proper selection of machining parameters is made. In this process, the geometric structure of the surface can be effectively modified. Proper selection of the process parameters (significantly influenced by the pressure, stroke, and tool diameter) allows for a favourable (geometrical surface structure) GSS (primarily to reduce the amount of surface roughness significantly).

(2) The use of a static determined, sequential, polyselective Hartley PS/DS-P:Ha3 plan enables clear identification of the interdependencies between key process parameters and the properties of the geometric structure of the surface.

(3) The ball burnishing process with hydrostatic tools leads to an improvement in the indicators of the geometric surface structure. In most cases, the 


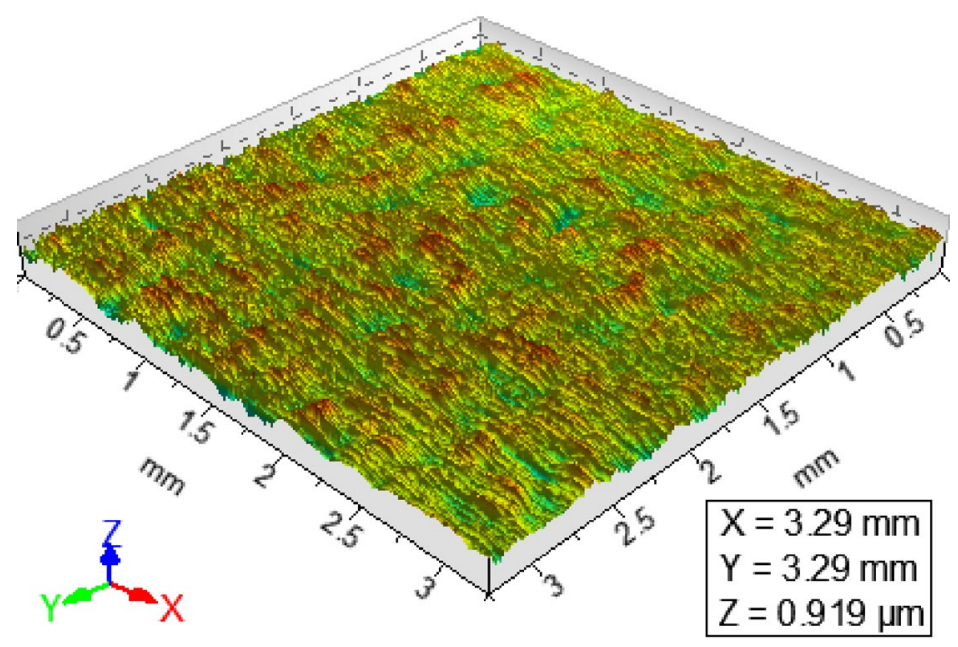

Sq: $0.0787 \mu \mathrm{m}$

Ssk: -0.227

Sku: 3.46

Sp: $0.421 \mu \mathrm{m}$

Sv: $0.498 \mu \mathrm{m}$

Sz: $0.919 \mu \mathrm{m}$

Sa: $0.0616 \mu \mathrm{m}$

Spd: $264 / \mathrm{mm}^{2}$

Spc: $7.82 / \mathrm{mm}$

Sk: $0.193 \mu \mathrm{m}$

Spk: $0.0653 \mu \mathrm{m}$

Svk: $0.0945 \mu \mathrm{m}$

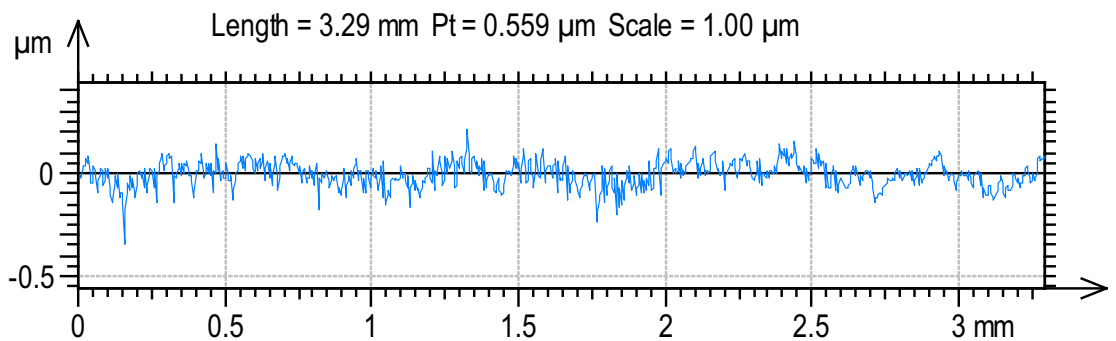

Figure 6 Topography and parameters of the surface in Expt. No. 11 after burnishing

Table 3 Comparison of surface texture parameters
after grinding and ball burnishing

after grinding and ball burnishing

\begin{tabular}{llll}
\hline $\begin{array}{llll}\text { Surface texture } \\
\text { parameters }\end{array}$ & \multicolumn{2}{l}{ Specimen } \\
\cline { 3 - 4 } & Grinding & \multicolumn{2}{l}{ Ball burnishing } \\
\cline { 3 - 4 } & & Min. & Max. \\
\hline Sq $(\mu \mathrm{m})$ & 0.488 & 0.0964 & 0.185 \\
Ssk & -0.245 & -0.726 & -0.143 \\
Sku & 3.12 & 3.21 & 5.73 \\
Sp $(\mu \mathrm{m})$ & 2.86 & 0.523 & 0.915 \\
Sv $(\mu \mathrm{m})$ & 2.79 & 0.536 & 1.63 \\
Sz $(\mu \mathrm{m})$ & 5.65 & 1.06 & 2.32 \\
Sa $(\mu \mathrm{m})$ & 0.387 & 0.0557 & 0.142 \\
Spd $\left(1 / \mathrm{mm}^{2}\right)$ & 910 & 219 & 959 \\
Spk $(\mu \mathrm{m})$ & 0.238 & 0.0745 & 0.135 \\
Svk $(\mu \mathrm{m})$ & 0.127 & 0.102 & 0.266 \\
\hline
\end{tabular}

result is an anisotropic surface, reduced roughness, and reduced values of amplitude parameters such as $\mathrm{Sa}$ and $\mathrm{Sz}$. The greatest impact on the values of indicators of the geometric structure results from the pressure, while smaller (but still significant) impacts result from the tool speed and line-to-line pitch.

(4) For the given conditions of this study, equations describing the relationships between processing parameters and surface texture parameters were determined. These relationships allow for the selection of appropriate parameters for the requirements of the ball burnishing of X38CrMoV51 steel samples, and also allows for process optimisation. 


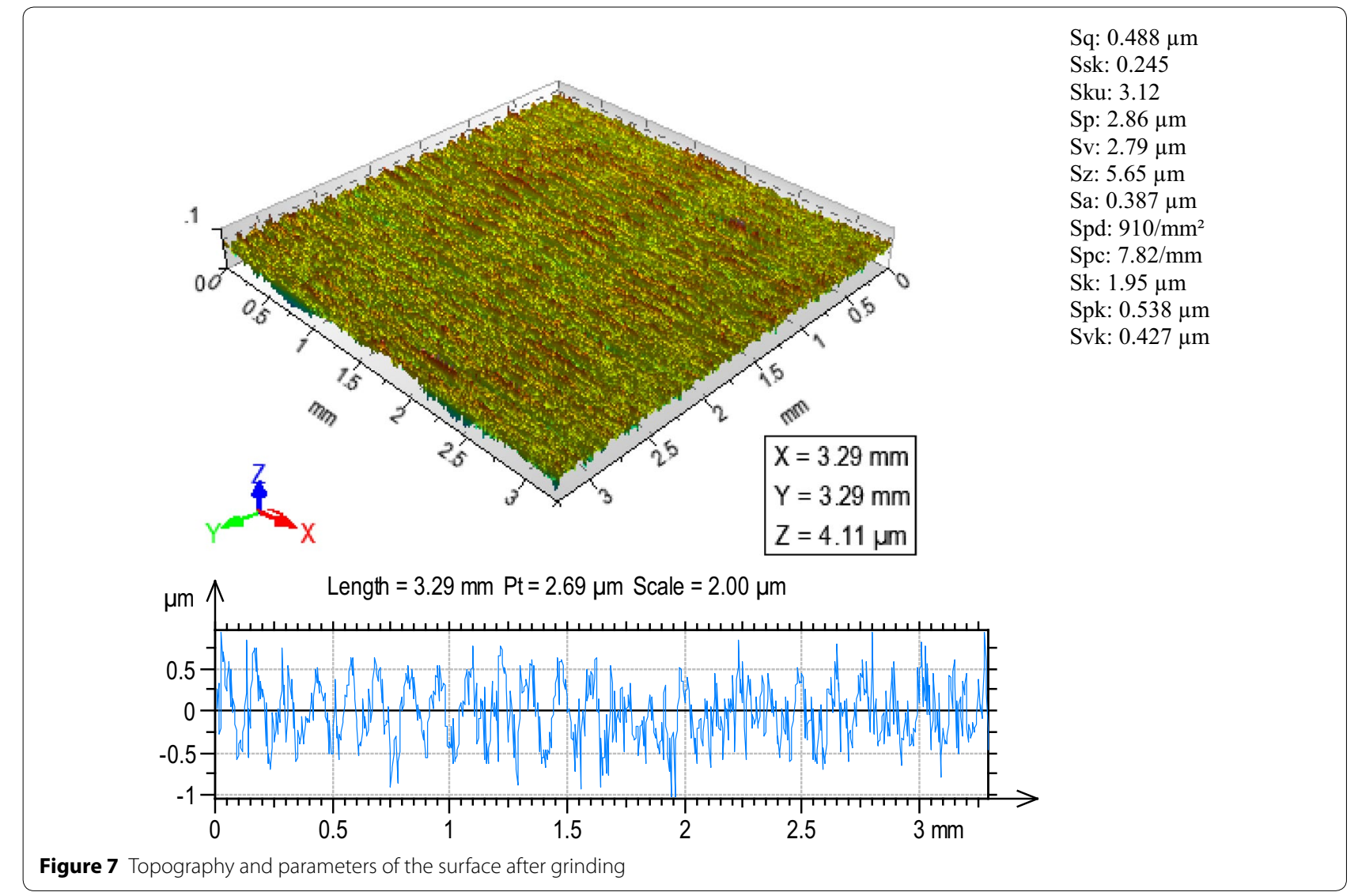

Table 4 Factor value results

\begin{tabular}{lllll}
\hline Expt. No. & $\begin{array}{l}\bar{y} \\
\text { (Sq) }\end{array}$ & $\begin{array}{l}\bar{y} \\
\text { (Sv) }\end{array}$ & $\begin{array}{l}\bar{y} \\
\text { (Sz) }\end{array}$ & $\begin{array}{l}\bar{y} \\
\text { (Sa) }\end{array}$ \\
\hline 1 & 0.103 & 0.659 & 1.44 & 0.0803 \\
2 & 0.11 & 0.622 & 1.14 & 0.0862 \\
3 & 0.106 & 0.536 & 1.06 & 0.0839 \\
4 & 0.149 & 1.51 & 2.3 & 0.113 \\
5 & 0.106 & 1.29 & 1.94 & 0.0815 \\
6 & 0.105 & 0.789 & 1.39 & 0.08 \\
7 & 0.15 & 1.63 & 2.32 & 0.114 \\
8 & 0.0964 & 0.639 & 1.27 & 0.0757 \\
9 & 0.185 & 1.28 & 2.2 & 0.142 \\
10 & 0.122 & 0.895 & 1.56 & 0.0946 \\
11 & 0.129 & 1.02 & 1.76 & 0.0986 \\
\hline
\end{tabular}

\section{Acknowledgements}

Not applicable.

\section{Authors' Contributions}

SS was in charge of the whole analyses and wrote the manuscript. The author read and approved the final manuscript.

\section{Authors' Information}

Slawomir Swirad, born in 1975, is currently a Ph.D. researcher at Rzeszow University of Technology, Poland. He received his master degree on mechanical engineering at the same university, in 2000.

\section{Competing Interests}

The authors declare that they have no competing interests.

\section{Funding}

Not applicable.

Received: 27 March 2019 Revised: 19 September 2019 Accepted: 25 October 2019

Published online: 07 November 2019

\section{References}

[1] Ch W, Chow A, Hartawan T, Wee K. Deep cold rolling of features on aeroengine components. Procedia CIRP, 2014, 13: 350-354.

[2] L N Lopez de Lacalle, A Lamikiz, J Munoa, et al. Quality improvement of ball-end milled sculptured surfaces by ball burnishing. International Journal of Machine Tools \& Manufacture, 2005, 45: 1659-1668.

[3] A Sagbas. Analysis and optimization of surface roughness in the ball burnishing process using response surface methodology and desirability function. Advances in Engineering Software, 2011, 42(11): 992-998.

[4] Luca L. Investigation into the use of ball burnishing of hard-ened steel components as a finishing process. USA: University of Toledo, 2002.

[5] L N Lopez de Lacalle, A Lamikiz, J A Sanchez, et al. The effect of ball burnishing on heat-treated steel and inconel 718 milled surfaces. International Journal of Advanced Manufacturing Technology, 2007, 32: 958-968.

[6] F J Shiou, C H Chen. Ultra-precision surface finish of NAK80 mold tool steel using sequential ball burnishing and ball polishing processes. Journal of Materials Processing Technology, 2008, 201: 554-559.

[7] P S Prevéy, N Jayaraman, R Ravindranath. Low plasticity burnishing (LPB) treatment to mitigate FOD and corrosion fatigue damage in 17-4 
PH stainless steel. Proceedings of the Tri-Service Corrosion Conference Las Vegas, USA, November 17-21, 2003.

[8] J Scheel, P S Prevéy, D Hornbach, Prevention of corrosion related failure of aircraft aluminum using an engineered residual stress field. $D O D$ Corrosion Conference, La Quinta, USA, 31 July-5 August, 2011.

[9] F Gharbi, S Sghaier, H Hamdi, et al. Ductility improvement of aluminum 1050A rolled sheet by a newly designed ball burnishing tool device. Int. J. Adv. Manuf. Technol., 2012, (60): 87-99.

[10] N S M El-Tayeb, K O Low, P V Brevern. Influence of roller burnishing contact width and burnishing orientation on surface quality and tribological behaviour of Aluminium 6061. Journal of Materials Processing Technology, 2007, 186: 272-278.

[11] A M Hassan, Z S Al-Dhifi. Improvement in the wear resistance of brass components by the ball burnishing process. Journal of Materials Processing Technology, 1999, 96(1-3): 73-80.

[12] M Salahshoor, Y B Guo. Surface integrity of magnesium-calcium implants processed by synergistic dry cutting-finish burnishing. Procedia Engineering, 2011, 19: 288-293.

[13] N S El-Tayeb, K O Low, P V Brevern. On the surface and tribological characteristics of burnished cylindrical Al-6061. Tribol. Int., 2009, 42: 320-326.

[14] D S Rao, H S Hebbar, M Komaraiah, et al. Investigations on the effect of ball burnishing parameters on surface hardness and wear resistance of HSLA dual-phase steels. Mater Manuf. Process, 2008, 23: 295-302.

[15] N H Loh, S C Tam, S Miyazawa. A study of the effects of ball burnishing parameters on surface roughness using factorial design. J. Mech. Work Technol., 1989, 18: 53-61.

[16] T A El-Taweel, $\mathrm{M} \mathrm{H}$ El-Axir. Analysis and optimization of the ball burnishing process through the Taguchi technique. Int. J. Adv. Manuf. Technol., 2009, 41: 301-310.

[17] F J Shiou, C C Hsu. Surface finishing of hardened and tempered stainless tool steel using sequential ball grinding, ball burnishing and ball polishing processes on a machining centre. J. Mater Process Technol., 2008, 205: 249-258.
[18] F J Shiou, C H Cheng. Ultra-precision surface finish of NAK80 mould tool steel using sequential ball burnishing and ball polishing processes. J. Mater Process Technol., 2008, 201: 554-559.

[19] S Swirad, D Wydrzynski, P Nieslony, et al. Influence of hydrostatic burnishing strategy on the surface topography of martensitic steel. Measurement 2019, 138: 590-601.

[20] S Swirad. Surface texture characterization of alpha-beta titanium alloy (Ti6Al4V) after hydrostatic burnishing, MATEC Web Conf., 2018, 189: 01001.

[21] S Swirad. High-precision finishing hard steel surfaces using hydrostatic burnishing tool. MATEC Web Conf., 2018, 249: 03002.

[22] L N López de Lacalle, A Lamikiz, J Muñoa, et al. Quality improvement of ball-end milled sculptured surfaces by ball burnishing. International Journal of Machine Tools and Manufacture, 2005, 45(15): 1659-1668.

[23] L N López de Lacalle, A Rodríguez, A Lamikiz, et al. Five-axis machining and burnishing of complex parts for the improvement of surface roughness. Mater. Manuf. Processes, 2011, 26: 997-1003.

[24] H O Hartley. Smallest composite design for quadratic response surface. Biometrics, 1959, 15: 611-624.

[25] M Korzynski. Metodyka eksperymentu. WNT, 2nd Ed. Warsaw 2017.

[26] S Swirad, RWdowik. Determining the effect of ball burnishing parameters on surface roughness using the Taguchi method. Procedia Manufacturing, 2019, 34: 287-292

[27] M Korzynski, J Lubas, S Swirad, et al., Surface layer characteristics due to slide diamond burnishing with a cylindrical-ended tool. Journal of Materials Processing Technology, 2011, 211(1):84-94.

[28] A Dzierwa, A P Markopoulos. Influence of ball-burnishing process on surface topography parameters and tribological properties of hardened steel. Machines, 2019, 7(1): 11

[29] ISO 25178-2:2012. Geometrical Product Specifications (GPS)—Surface Texture: Areal—Part 2: Terms, Definitions and Surface Texture Parameters; ISO: Geneva, Switzerland, 2011.

\section{Submit your manuscript to a SpringerOpen ${ }^{\circ}$ journal and benefit from:}

- Convenient online submission

- Rigorous peer review

- Open access: articles freely available online

- High visibility within the field

- Retaining the copyright to your article

Submit your next manuscript at $\boldsymbol{\nabla}$ springeropen.com 